\title{
Should the tip-apex distance (TAD) rule be modified for the proximal femoral nail antirotation (PFNA)? A retrospective study
}

Andrej N Nikoloski ${ }^{* *}$, Anthony L Osbrough ${ }^{1}$ and Piers J Yates ${ }^{1,2,3}$

\begin{abstract}
Background: Unstable proximal femoral fractures are common and challenging for the orthopaedic surgeon. Often, these are treated with intramedullary nails. The most common mode of failure of any device to treat these fractures is cut-out. The Synthes proximal femoral nail antirotation (PFNA) is unique because it is the only proximal femoral intramedullary nail which employs a helical blade in lieu of a lag screw. The optimal tip-apex distance is 25 $\mathrm{mm}$ or less for a dynamic hip screw. The optimal blade tip placement is not known for the PFNA.

Aim: The aim of this study is to determine if the traditional tip-apex distance rule $(<25 \mathrm{~mm})$ applies to the PFNA.

Method: A retrospective study of all proximal femoral fractures treated with the PFNA in Western Australian public teaching hospitals between August 2006 and October 2007 was performed. Cases were identified from company and theatre implant use records. Patient demographic data was obtained from hospital records. Fractures were classified according to Arbeitsgemeinschaft für Osteosynthesefragen/Association for the Study of Internal Fixation. Fracture reduction, distal locking type and blade position within the head (tip-apex distance and Cleveland zone) were recorded from the intraoperative and immediate postoperative radiographs. Postoperative radiographs obtained in the routine treatment of patients were studied for review looking primarily for cut-out. Clinical outcomes were measured with the Oxford hip score.
\end{abstract}

Results: One hundred eighty-eight PFNAs were implanted during the study period, with 178 cases included in this study. Ninety-seven patients could be followed up clinically. There were 18 surgical implant-related failures (19\%). The single most common mode of failure was cut-out in six cases (6.2\%). Three cut-outs (two medial perforation and one varus collapse) occurred with tip-apex distance (TAD) less than $20 \mathrm{~mm}$. There was no cut-out in cases where the TAD was from 20-30 mm. There were three implant-related failures (nail fracture, missed nail and loose locking screw), four implant-related femoral fractures, two non-unions, two delayed unions and one loss of reduction.

Conclusion: The PFNA is a suitable fixation device for the treatment of unstable proximal femoral fractures. There were still a relatively large number of cut-outs, and the tip-apex distance in the failures showed a bimodal distribution, not like previously demonstrated with dynamic hip screw. We propose that the helical blade behaves differently to a screw, and placement too close to the subchondral bone may lead to penetration through the head.

Keywords: Proximal, Femur, Fracture, Intramedullary, Nail, Fixation, PFNA, TAD

\footnotetext{
* Correspondence: dr.anikoloski@gmail.com

${ }^{1}$ Fremantle Hospital Orthopaedic Unit, Fremantle Hospital, Level 6, B Block,

Alma Street, Fremantle, Western Australia 6160, Australia

Full list of author information is available at the end of the article
} 


\section{Introduction}

Unstable proximal femoral fractures are common and challenging for the orthopaedic surgeon. The aim of the surgical treatment of these fractures is to achieve stable fracture fixation that will allow early weight bearing. Many different devices have been developed, yet mechanical failures still occur. Cephalomedullary nails are now favoured in most Western Australian teaching hospitals for the treatment of unstable proximal femur fractures. The complication rate is quoted as being from $15 \%$ to $20 \%$, with the most common mode of failure being screw or blade cut-out [1-3]. In biomechanical studies, the spiral blade of the Synthes proximal femoral nail antirotation (PFNA; Synthes GmbH, Oberdorf, Switzerland) has shown a superior cut-out resistance, which may translate into fewer cut-outs in the clinical setting $[4,5]$. The technique guide for this implant suggests a distance from the blade tip to the joint level of $10 \mathrm{~mm}$ in the anteroposterior and lateral projections [6]. This corresponds to a tip-apex distance of $20 \mathrm{~mm}$. When using a sliding hip screw and plate construct, a tip-apex distance (TAD) of less than $25 \mathrm{~mm}$ and centre-centre positioning has been established as a major factor to minimise the risk of cut-out [7]. There is little similar data on the optimal placement of the blade for intramedullary devices and none for blade based intramedullary devices such as the PFNA.

\section{Aim}

The aim of the study is to determine if the traditional tip-apex distance rule $(<25 \mathrm{~mm})$ applies to a helical blade device.

\section{Patients and methods}

We retrospectively identified 187 patients who had 188 fractures treated with the Synthes PFNA at the three Western Australian tertiary teaching hospitals between August 2006 and October 2007. These were identified via company and hospital theatre records. Ten patients were excluded because they either had the nail implanted as fracture prophylaxis for a tumour or as an intracapsular or diaphyseal region fracture.

The medical records and picture archiving system (AGFA Impax 5, Ridgefield Park, NJ, USA) of the remaining 178 patients were accessed to obtain clinical data and radiographs for analysis. Preoperative radiographs were used to classify fractures according to Arbeitsgemeinschaft für Osteosynthesefragen/Association for the Study of Internal Fixation (AO/ASIF). Immediate postoperative radiographs, when available, were analysed for reduction quality and blade tip position as per Cleveland and TAD [7,8]. All measurements were performed by the chief author. In those cases where an immediate (day 1 ) postoperative X-ray was not available, this data was obtained from the fluoroscopy images. Operation notes were reviewed to confirm that the surgery followed the manufacturer's surgical technique manual [6]. All subsequent X-ray images for each patient were reviewed looking primarily for cut-out (varus collapse or medial perforation) as well as any other radiologically apparent complication. The clinical follow-up consisted of outpatient clinical follow-up with Oxford hip score for those patients that could attend. In our hospitals, we use the Oxford hip score routinely to assess pain and function in patients with hip pathology.

Data was analysed for descriptive statistics using SPSS statistical software version 11.0 (SPSS Inc. Chicago, IL, USA). We used Pearson's chi-squared test or Fisher's exact test for comparing differences in categorical variables.

\section{Results}

Patient demographics and characteristics are provided in Table 1 . We analysed the preoperative radiographs to classify fractures according to AO/ASIF (Figure 1). The majority, 152 (95.5\%), were unstable fracture types; of these, 31A2 (47.7\%) and 31A3 (37.6\%) were dominant. There were $13(7.3 \%)$ fractures of the subtrochanteric region (31A3.3, 32A).

The nail used was short $(240 \mathrm{~mm})$ in $136(76.4 \%)$ and long $(>240 \mathrm{~mm})$ in $42(23.6 \%)$ cases. Distal locking was static in $146(82 \%)$ and dynamic in $32(18 \%)$ cases. Postoperative treatment for all patients was full weight bearing.

Postoperative radiographs were analysed for reduction quality, TAD and Cleveland zone. Reduction quality was graded as anatomical, near-anatomical and non-anatomical and was assessed by the chief investigator. The reduction was anatomical in 123 (69.1\%), near-anatomical in 45 (25.2\%) and non-anatomical in 10 (5.6\%) cases.

The TAD was assessed on the immediate postoperative radiographs, using the method described by Baumgaertner [9]. The TAD ranged from 7 to $45 \mathrm{~mm}$, with 96 (53.9\%) cases under $25 \mathrm{~mm}$ (Figure 2).

The location of the blade within the head was recorded as per the Cleveland method, on a lateral X-ray of the femoral head, divided into nine sections [8]. The Cleveland zone 5 (centre-centre) was the most common

\section{Table 1 Patient characteristics}

\begin{tabular}{lc}
\hline & Value \\
\hline Age (years) & \\
Mean & 81.5 \\
Range & 36 to 99 \\
Gender $(n(\%))$ & \\
$\quad$ Female & $128(71.9)$ \\
Male & $50(28.1)$ \\
Side $(n(\%))$ & \\
Left & $107(60.1)$ \\
Right & $81(45.5)$ \\
\hline
\end{tabular}




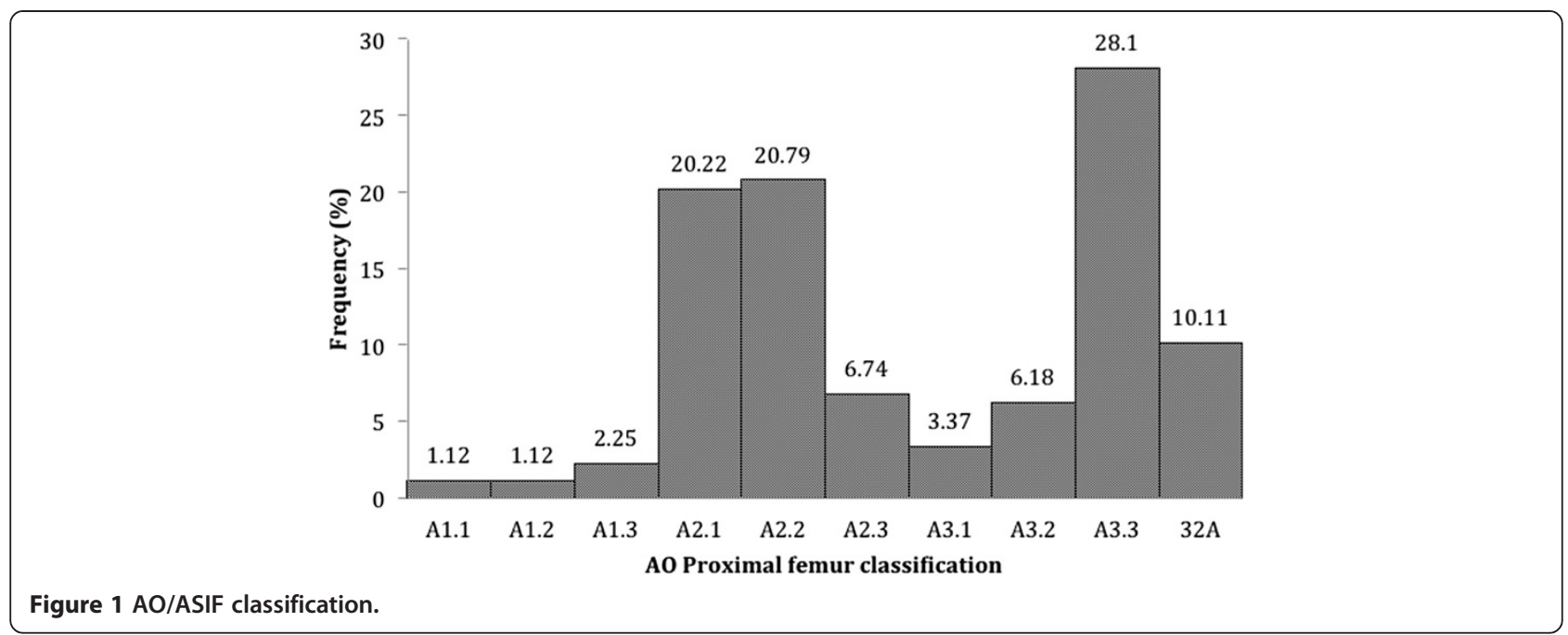

placement of the tip of the blade on postoperative radiographs, accounting for 98 (55.1\%) of the cases. The second most common location was zone 2 (centresuperior) with $31(17.4 \%)$ cases (Figure 3$)$.

The average time to clinical follow-up was 10 months. Within the follow-up period, 45 (24\%) patients died of medical comorbidities, and $36(19 \%)$ patients could not be contacted or were unable or unwilling to attend the outpatient clinic. The total number of patients who could be clinically followed-up was thus 97 . For the patients who had clinical follow-up, the mean Oxford hip score was 27, ranging from 12 to 45 (out of 48).

\section{Complications}

There were 18 out of 97 (18.6\%) surgical implant-related complications identified in the study. There were six (6.2\%) cases of cut-out. We saw two patterns of cut-out: cephalad cut-out (varus head collapse) and axial cut-out (medial or anterosuperior migration). Cephalad cut-out occurred in 4 (4.1\%) and axial cut-out (medial perforation) in 2 (2.1\%) of 97 cases (Figures 4 and 5). All were in unstable fracture types, four in fracture type 31A2 and two in 31A3. The reduction was anatomical or near anatomical in five of the cases and non-anatomical in one case. Three of the cephalad cut-outs had a TAD greater than $30 \mathrm{~mm}$, and in one case, it was $15 \mathrm{~mm}$. The two axial cut-outs (medial perforations) occurred where the TAD was less than $20 \mathrm{~mm}$. No failures occurred where the TAD was in the interval of 20 to $30 \mathrm{~mm}$ (Figure 6).

When analysed in three groups: TAD $0-20 \mathrm{~mm}$, TAD 20-30 mm, TAD $>30 \mathrm{~mm}$, there was a statistically significant difference in the frequency of cut-out between the cases with TAD $0-20 \mathrm{~mm}$ and TAD $20-30 \mathrm{~mm}$ $(p=0.0293)$, but not between TAD $0-20 \mathrm{~mm}$ and TAD $>30 \mathrm{~mm}(p=0.3707)$ (Table 2).

The Cleveland zone distribution of the blades which cut-out were zone 5 (centre, centre) in three cases, zone 2 (centre, superior) in one case, zone 4 (centre, anterior) in one case and zone 1 (superior, posterior) in one case. In the cases of failure associated with a TAD 0-20 mm, the position of the blade was in zone 5 (centre, centre).

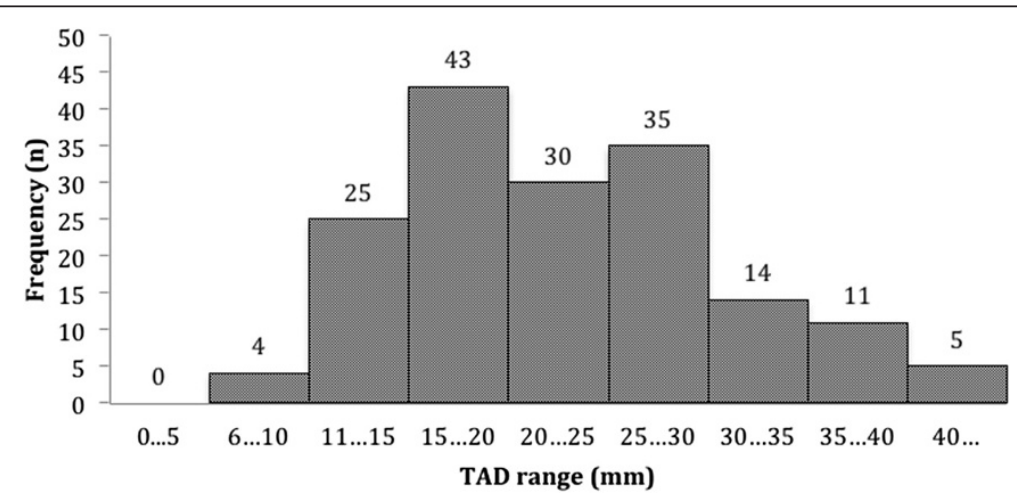

Figure 2 TAD distribution. 


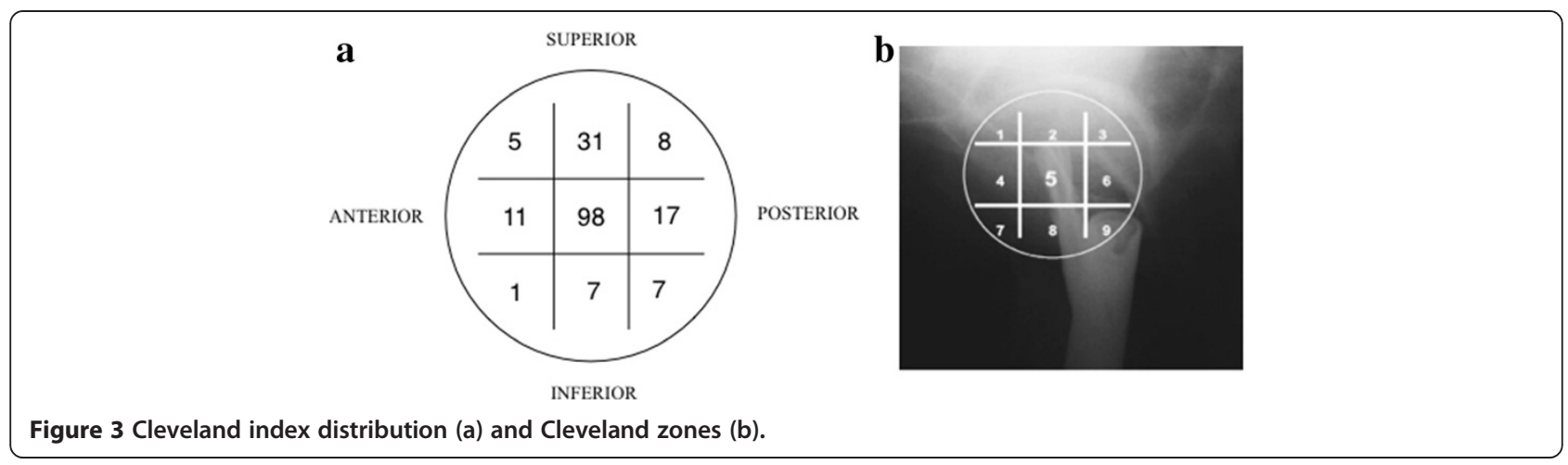

There was no statistically significant difference in cutout rates between the nine different zones $(p=0.565)$.

Other complications in the order of frequency were three intraoperative femur fractures (1.7\% of all cases), two periprosthetic fractures (distal to the tip of the nail), two cases of delayed union (1.1\%) and two cases of nonunion $(1.1 \%)$. The intraoperative femur fractures all occurred when using long nails. Both non-unions occurred in subtrochanteric fractures. There were no infections.

\section{Discussion}

Optimal fixation of proximal femoral fractures is still controversial. There is no evidence in the literature demonstrating that an intramedullary nail is superior to extramedullary devices, such as a DHS, when used for stable fracture types [1,9-12]. Some studies comparing the gamma nail to the DHS show an increased rate of complications including femur fracture with the use of an intramedullary device [13]. Biomechanically, intramedullary devices have been shown to be superior for unstable fracture types. A recent prospective randomised study comparing the PFNA to the DHS in mainly unstable fracture patterns found no statistically significant difference in complications [13]. The predominant trend in Western Australian tertiary centres is to
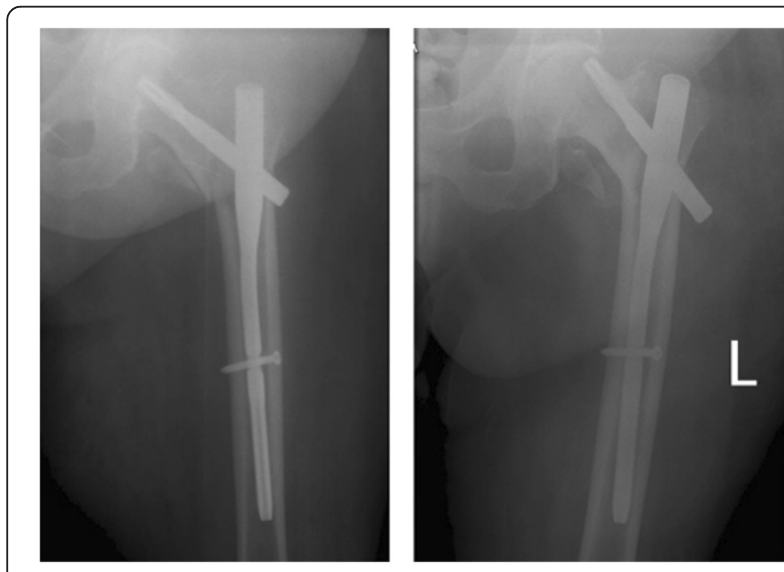

Figure 4 Cut-out with TAD $42 \mathrm{~mm}$. Blade has migrated superiorly. use the PFNA in unstable fractures of AO/ASIF type $31 \mathrm{~A} 2$ and $31 \mathrm{~A} 3$. We found that our complication rate is comparable to other studies of the PFNA [5,14-18], but that it is also similar to that with older nail designs [3]. The change to a helical blade with the introduction of the PFNA (and TFN in other markets) was intended to reduce the likelihood of cut-out and to eliminate the occurrence of the Z-effect mode of failure of the old PFN. Several biomechanical studies have supported this $[4,19]$. The phenomenon of cut-out has however not been eliminated and is in fact still the most common mode of failure.

We had 6 (6.2\%) cases of cut-out in our series of 178. Several clinical studies report cases of cut-out with the PFNA. Brunner et al. reported 3 (25\%) cases of cut-out out of 12 [18]. They raised the possibility that the mode of cut-out of the PFNA may be related to its helical blade design, which may result in medial perforation of the subchondral bone. Mereddy et al. had 2 (3.2\%) cases in their series of 62 [17]. They reported their TAD as $<20 \mathrm{~mm}$ in $79 \%$ of the total cases but did not report

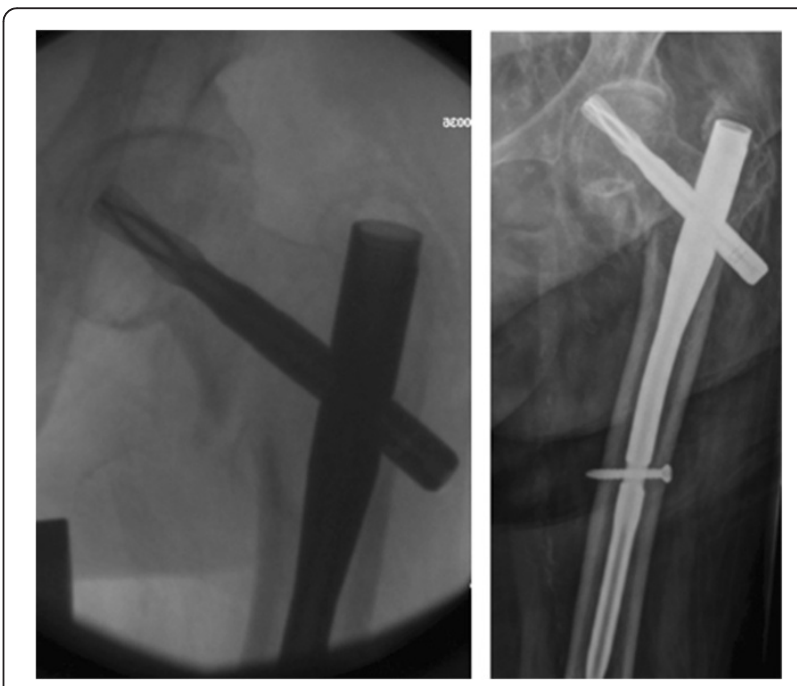

Figure 5 Fluoroscopy image of PFNA with TAD of $9 \mathrm{~mm}$. Blade has migrated axially. 


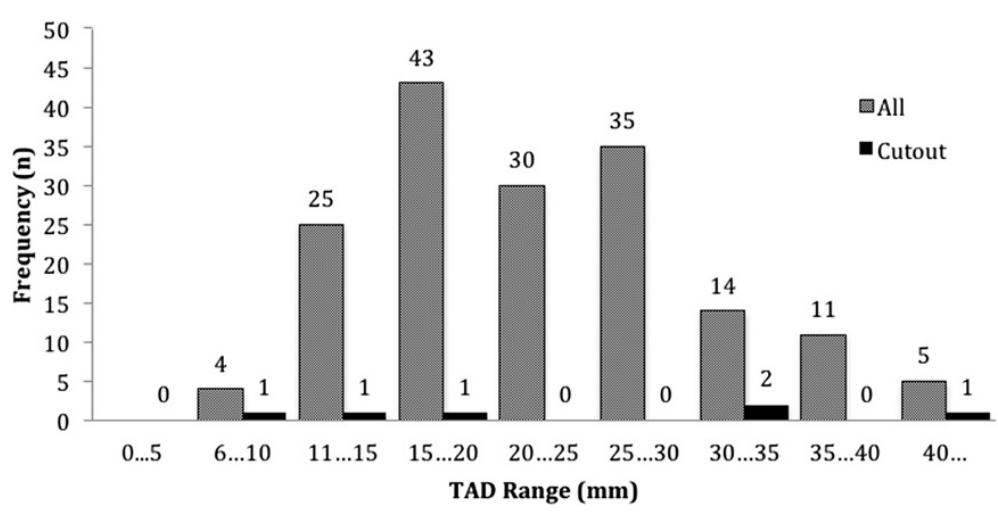

Figure 6 Distribution of TAD in cut-out and all cases.

what the TAD was in cases of cut-out. Penzkofer et al. reported $3(4.5 \%)$ cut-outs in their cohort of 66 pertrochanteric and subtrochanteric fractures treated with PFNA [20]. A randomised trial by Wild et al. compared the PFNA with a two-screw type intramedullary nail (Targon PF, Aesculap, Tuttlingen, Germany) and had $3(7.5 \%)$ cases of cut-out in the PFNA group of 40 and $2(5 \%)$ in their group of 40 treated with the Targon PF nail [21]. Takigami et al. had $1(2 \%)$ cut-out in their series of 50 pertrochanteric fractures treated with PFNA for unstable fractures [22].

Several authors however have reported much lower rates of cut-out, such as Liu et al. and Pu et al., who had no cases of cut-out in their series of 125 and 87, respectively $[23,24]$. Liu et al. attributed their lack of cut-out to their more conservative post-op rehabilitation regime. $\mathrm{Pu}$ et al. reported an average TAD of $16.8 \mathrm{~mm}$, but suggested not putting the helical blade tip closer than 10 $\mathrm{mm}$ from subchondral bone and using a shorter blade in order to avoid head perforation. Simmermacher have the largest series to date, with a reported cut-out rate of 4 (1.2\%) out of 313 cases [5].

\section{Optimal blade position}

It has been assumed that following the rules established for DHS placement should yield similarly good results with the PFNA. The technique guide for the Synthes PFNA suggests inserting the guide wire to $5-10 \mathrm{~mm}$ from subchondral bone on the AP and lateral views, which would yield a TAD of $10-20 \mathrm{~mm}$ in the case of centre-centre positioning. Our study is one of several recently that show that cut-out still occurs, despite a tip-

Table 2 Tip-apex distance and cut-out frequency

\begin{tabular}{lcc}
\hline TAD $(\mathbf{m m})$ & Cut-out $(\boldsymbol{n})$ & No cut-out $(\boldsymbol{n})$ \\
\hline $0-20$ & 3 & 31 \\
$20-30$ & 0 & 74 \\
$>30$ & 3 & 73 \\
\hline
\end{tabular}

apex distance that would be considered ideal for a sliding hip screw. In our series, three cut-outs (two medial perforations and one cephalad cut-out) occurred in cases where the TAD was less than $25 \mathrm{~mm}$ and with centrecentre positioning of the tip of the blade. There were no cut-outs in the range of $20-30 \mathrm{~mm}$, and this would be considered 'too far' from the apex when using a sliding hip screw such as a DHS. The other three cut-outs were seen in cases where the TAD was more than $30 \mathrm{~mm}$. The failures in these three cases were cephalad cut-out.

One hypothesis is that due to the different geometry of the blade compared to a threaded tip screw, the blade 'behaves' differently under load; this potentially results in medial perforation or axial cut-out when inserted too close to the sub-chondral bone. In Simmermacher's large multicentre series, the phenomenon of medial blade migration was attributed to patients falling directly onto the trochanteric region, presumably axially loading the head component of the implant [5]. They did not report their target TAD or the TAD in those cases of cut-out. A recent biomechanical study by Born et al. comparing threaded screw and helical blade constructs in a model of pertrochanteric fracture fixation using polyurethane femoral heads found that the blade device is more prone to cut-out [25]. This is in contrast to previous biomechanical studies $[4,19]$. The Born et al. testing set-up is unique in that it multiaxially loads the constructs, alluding to the likely reason for the clinical observations of axial migration of helical blades within the head. This study proposes that the blade device, due to its shape, presents a lesser contact surface to the bone in the axial direction. They report an axial contact surface of $75 \mathrm{~mm}^{2}$ for the PFNA blade and $300 \mathrm{~mm}^{2}$ for the gamma 3 screw. In a recent trial comparing the PFNA with the gamma 3 nail involving 136 unstable proximal femoral fractures, $\mathrm{Xu}$ et al. found no cut-out in both groups and similar overall outcomes [26].

We want to raise awareness of the possibility that the helical blade behaves differently to a screw in the femoral head and that following the traditional tip-apex distance 
recommendation needs to be further validated and even modified when using a blade, due to the risk of medial perforation (axial cut-out). Our results suggest that the tipapex distance for helical blade-based proximal femoral nails should be $20-30 \mathrm{~mm}$. Zhou and Chang wrote a letter to the editor coming to a similar conclusion based on their experiences from their centre and analysis of the literature [27]. In their opinion, the optimal tip-apex distance for the helical blade should be $20-25 \mathrm{~mm}$.

\section{Conclusion}

We believe that the TAD rule of $<25 \mathrm{~mm}$ should not apply for the PFNA. We suggest avoiding a TAD $<20 \mathrm{~mm}$ due to possible axial cut-out (medial migration) and avoiding a TAD $>30 \mathrm{~mm}$ to avoid cephalad cut-out. We would recommend that the surgical technique guide for the Synthes PFNA be revised to take this into account.

We acknowledge that the study is limited by its retrospective design, short period of follow-up, as well as a large number of patients lost to follow-up. Some of these downfalls are inherent in the population as elderly patients with hip fractures have a higher incidence of comorbidities and thus medical complications subsequent to their fall and surgery.

\section{Abbreviations}

PFNA: Proximal femoral nail antirotation; TAD: Tip-apex distance.

\section{Competing interests}

The senior author (PJY) is a member of the AO Foundation faculty and has received research funding and department grants from Synthes. This study was not financed or supported by any company or organization. The other authors have no competing interests.

\section{Authors' contributions}

ANN designed the study, collected and analysed the data and drafted the manuscript. ALO collected the data. PJY conceived the study and assisted in drafting the manuscript. All authors read and approved the final manuscript.

\section{Acknowledgements}

This study and the manuscript preparation were financed solely by the chief author (ANN).

\section{Author details}

${ }^{1}$ Fremantle Hospital Orthopaedic Unit, Fremantle Hospital, Level 6, B Block, Alma Street, Fremantle, Western Australia 6160, Australia. ${ }^{2}$ Orthopaedic Surgery, Fremantle Hospital, University of Western Australia, Crawley, Western Australia 6009, Australia. ${ }^{3}$ Fremantle and Kaleeya University Hospitals, East Fremantle, Western Australia 6158, Australia.

Received: 23 June 2013 Accepted: 24 September 2013 Published: 17 October 2013

\section{References}

1. Parker MJ, Handoll HH: Gamma and other cephalocondylic intramedullary nails versus extramedullary implants for extracapsular hip fractures. Cochrane Library Database System Rev 2010, 9:CD000093. doi:10.1002/ 14651858.CD000093.pub5.

2. Klinger HM, Baums MH, Eckert M, Neugebauer R: A comparative study of unstable per- and intertrochanteric femoral fractures treated with dynamic hip screw (DHS) and trochanteric butt-press plate vs. proximal femoral nail (PFN). Zentralblatt fur Chirurgie 2005, 130(4):301-306.

3. Windolf J, Hollander DA, Hakimi M: Pitfalls and complications in the use of the proximal femoral nail. Langenbecks Archiv Surg 2005, 390:59-65.
4. Sommers MB, Roth C, Hall H, Kam BC, Ehmke LW, Krieg JC, Madey SM, Bottlang M: A laboratory model to evaluate cutout resistance of implants for pertrochanteric fracture fixation. J Orthop Trauma 2004, 18:361-368.

5. Simmermacher RKJ, Ljungqvist J, Bail H, Hockertz T, Vochteloo AJ, Ochs U, Werken C, AO - PFNA studygroup: The new proximal femoral nail antirotation (PFNA) in daily practice: results of a multicentre clinical study. Injury 2008, 39(8):932-939.

6. PFNA: Leading the way to optimal stability: Synthes. Original instruments and implants of the association for the study of internal fixation. $\mathrm{AO} /$ ASIF. Technique guide. Stratec Med 2004:1-44.

7. Baumgaertner MR, Curtin SL, Lindskog DM, Keggi JM: The value of the tipapex distance in predicting failure of fixation of peritrochanteric fractures of the hip. J Bone Joint Surg Am 1995, 77(7):1058-1064.

8. Cleveland M, Thompson F, Wilson $H$, Ishizuka T: A ten-year analysis of intertrochanteric fractures of the femur. J Bone Joint Surg Br 1959, 41-A:1399-1408.

9. Baumgaertner MR, Curtin SL, Lindskog DM: Intramedullary versus extramedullary fixation for the treatment of intertrochanteric hip fractures. Clin Orthop Relat Res 1998, 348:87-94.

10. Lenich A, Mayr E, Ruter A, Möckl C, Füchtmeier B: First results with the trochanter fixation nail (TFN): a report on 120 cases. Arch Orthop Trauma Surg 2006, 126:706-712.

11. Saudan M, Lübbeke A, Sadowski C, Riand N, Stern R, Hoffmeyer P: Pertrochanteric fractures: is there an advantage to an intramedullary nail? A randomized, prospective study of 206 patients comparing the dynamic hip screw and proximal femoral nail. J Orthop Trauma 2002, 16(6):386-393.

12. Butt MS, Krikler SJ, Nafie S, Ali MS: Comparison of dynamic hip screw and gamma nail: a prospective, randomized, controlled trial. Injury 1995, 26:615-618.

13. Zou J, Xu Y, Yang $\mathrm{H}$ : A comparison of proximal femoral nail antirotation and dynamic hip screw devices in trochanteric fractures. J Int Med Res 2009, 37(4):1057-1064.

14. Bridle $\mathrm{SH}$, Patel $\mathrm{AD}$, Bircher $\mathrm{M}$, Calvert P: Fixation of intertrochanteric fractures of the femur. A randomised prospective comparison of the gamma nail and the dynamic hip screw. J Bone Joint Surg Br 1991, 73:330-334.

15. Jones HW, Johnston P, Parker M: Are short femoral nails superior to the sliding hip screw? A meta-analysis of 24 studies involving 3279 fractures. Int Orthop 2006, 30:69-78.

16. Gardner MJ, Stephen M, Briggs A, Kopjar B, Helfet DL, Lorich DG: Radiographic outcomes of intertrochanteric hip fractures treated with the trochanteric fixation nail. Injury 2007, 38:1189-1196.

17. Mereddy P, Kamath S, Ramakrishnan M, Malik H, Donnachie N: The AO/ASIF proximal femoral nail antirotation (PFNA): a new design for the treatment of unstable proximal femoral fractures. Injury 2009, 40(4):428-432

18. Brunner A, Jockel JA, Babst R: The PFNA proximal femur nail in treatment of unstable proximal femur fractures -3 cases of postoperative perforation of the helical blade into the hip joint. J Orthop Trauma 2008 22(10):731-736

19. Strauss E, Frank J, Lee J, Kummer F, Tejwani N: Helical blade versus sliding hip screw for treatment of unstable intertrochanteric hip fractures: a biomechanical evaluation. Injury 2006, 37(10):984-989.

20. Penzkofer J, Mendel T, Bauer C, Brehme K: Treatment results of pertrochanteric and subtrochanteric femoral fractures: a retrospective comparison of PFN and PFNA. Der Unfallchirurg 2009, 112(8):699-705.

21. Wild M, Jungbkuth $P$, Thelen S, Laffrée $Q$, Gehrmann S, Betsch M, Windolf J, Hakimi M: The dynamics of proximal femoral nails: a clinical comparison between PFNA and Targon PF. Orthop 2010, 33(8):10.

22. Takigami I, Matsumoto K, Ohara A, Yamanaka K, Naganawa T, Ohashi M, Date K, Shimizu K: Treatment of trochanteric fractures with the PFNA (proximal femoral nail antirotation) nail system - report of early results. Bull New York Univ Hosp Joint Dis 2008, 66(4):276-279.

23. Liu Y, Tao R, Liu F, Wang Y, Zhou Z, Cao Y, Wang H: Mid-term outcomes after intramedullary fixation of peritrochanteric femoral fractures using the new proximal femoral nail antirotation (PFNA). Injury 2010, 41:810-817.

24. Pu JS, Liu L, Wang GL, Fang Y, Yang TF: Results of the proximal femoral nail anti-rotation (PFNA) in elderly Chinese patients. Int Orthop 2009, 33(5):1441-1444. 
25. Born C, Karich B, Bauer C, von Oldenburg G, Augat P: Hip screw migration testing: first results for hip screws and helical blades utilizing a new oscillating test method. J Orthop Res 2011, 29(5):760-766.

26. Xu Y, Geng D, Yang H, Wang M, Zhu G: Treatment of unstable proximal femoral fractures: comparison of the proximal femoral nail antirotation and gamma nail 3. Orthop 2010, 33(7):473.

27. Zhou JQ, Chang SM: Failure of PFNA: helical blade perforation and tipapex distance. Injury 2012, 43(7):1227-1228.

doi:10.1186/1749-799X-8-35

Cite this article as: Nikoloski et al: Should the tip-apex distance (TAD)

rule be modified for the proximal femoral nail antirotation (PFNA)? A

retrospective study. Journal of Orthopaedic Surgery and Research 2013 8:35.

\section{Submit your next manuscript to BioMed Central} and take full advantage of:

- Convenient online submission

- Thorough peer review

- No space constraints or color figure charges

- Immediate publication on acceptance

- Inclusion in PubMed, CAS, Scopus and Google Scholar

- Research which is freely available for redistribution 